\title{
Genetic diversity of Microsporidia in the circulatory system of endemic amphipods from different locations and depths of ancient Lake Baikal
}

\author{
Mariya Dimova ${ }^{1}$, Ekaterina Madyarova ${ }^{1,2}$, Anton Gurkov ${ }^{1,2}$, Polina Drozdova ${ }^{1}$, Yulia Lubyaga ${ }^{1,2}$, Elizaveta \\ Kondrateva $^{1}{ }^{\text {, Renat Adelshin }}{ }^{1,3}$, Maxim Timofeyev ${ }^{\text {Corresp. } 1}$ \\ 1 Irkutsk State University, Irkutsk, Russia \\ 2 Baikal Research Centre, Irkutsk, Russia \\ 3 Irkutsk Anti-Plague Research Institute of Siberia and Far East, Irkutsk, Russia \\ Corresponding Author: Maxim Timofeyev \\ Email address: m.a.timofeyev@gmail.com
}

Endemic amphipods (Amphipoda, Crustacea) of the most ancient and large freshwater Lake Baikal (Siberia, Russia) are a highly diverse group comprising $>15 \%$ of all known species of continental amphipods. The extensive endemic biodiversity of Baikal amphipods provides the unique opportunity to study interactions and possible coevolution of this group and their parasites, such as Microsporidia. In this study, we investigated microsporidian diversity in the circulatory system of 22 endemic species of amphipods inhabiting littoral, sublittoral and deep-water zones in all three basins of Lake Baikal. Using molecular genetic techniques, we found microsporidian DNA in two littoral (Eulimnogammarus verrucosus, E. cyaneus), two littoral/sublittoral (Pallasea cancellus, E. marituji) and two sublittoral/deep-water (Acanthogammarus lappaceus longispinus, $A$. victorii maculosus) endemic species. Twenty sequences of the small subunit ribosomal (SSU) rDNA were obtained from the haemolymph of the six endemic amphipod species sampled from 0-60 m depths at the Southern Lake Baikal's basin (only the Western shore) and at the Central Baikal. They form clusters with similarity to Enterocytospora, Cucumispora, Dictyocoela, and several unassigned Microsporidia sequences, respectively. Our sequence data show similarity to previously identified microsporidian DNA from inhabitants of both Lake Baikal and other water reservoirs. The results of our study suggest that the genetic diversity of Microsporidia in haemolymph of endemic amphipods from Lake Baikal does not correlate with host species, geographic location or depth factors but is homogeneously diverse. 
1 Genetic diversity of Microsporidia in the circulatory system of endemic amphipods from 2 different locations and depths of ancient Lake Baikal

3

5 Mariya Dimova $^{1}$, Ekaterina Madyarova ${ }^{1,2}$, Anton Gurkov ${ }^{1,2}$, Polina Drozdova ${ }^{1}$, Yulia Lubyaga ${ }^{1,2}$, Elizaveta Kondrateva $^{1}$, Renat Adelshin ${ }^{1,3}$, Maxim Timofeyev ${ }^{1}$

${ }^{1}$ Irkutsk State University, Irkutsk, Russia

9

${ }^{2}$ Baikal Research Centre, Irkutsk, Russia

${ }^{3}$ Irkutsk Anti-Plague Research Institute of Siberia and Far East, Irkutsk, Russia

13 Corresponding Author:

14 Maxim Timofeyev ${ }^{1}$

15

16 Email address: m.a.timofeyev@gmail.com

17 


\section{Abstract}

Endemic amphipods (Amphipoda, Crustacea) of the most ancient and large freshwater

21 Lake Baikal (Siberia, Russia) are a highly diverse group comprising $>15 \%$ of all known species

22 of continental amphipods. The extensive endemic biodiversity of Baikal amphipods provides the

23 unique opportunity to study interactions and possible coevolution of this group and their

24 parasites, such as Microsporidia. In this study, we investigated microsporidian diversity in the

25 circulatory system of 22 endemic species of amphipods inhabiting littoral, sublittoral and deep-

26 water zones in all three basins of Lake Baikal. Using molecular genetic techniques, we found

27 microsporidian DNA in two littoral (Eulimnogammarus verrucosus, E. cyaneus), two

28 littoral/sublittoral (Pallasea cancellus, E. marituji) and two sublittoral/deep-water

29 (Acanthogammarus lappaceus longispinus, A. victorii maculosus) endemic species. Twenty

30 sequences of the small subunit ribosomal (SSU) rDNA were obtained from the haemolymph of

31 the six endemic amphipod species sampled from 0-60 m depths at the Southern Lake Baikal's

32 basin (only the Western shore) and at the Central Baikal. They form clusters with similarity to

33 Enterocytospora, Cucumispora, Dictyocoela, and several unassigned Microsporidia sequences,

34 respectively. Our sequence data show similarity to previously identified microsporidian DNA

35 from inhabitants of both Lake Baikal and other water reservoirs. The results of our study suggest

36 that the genetic diversity of Microsporidia in haemolymph of endemic amphipods from Lake

37 Baikal does not correlate with host species, geographic location or depth factors but is 38 homogeneously diverse.

\section{Introduction}



is the largest (by volume; $23,000 \mathrm{~km}^{3}$ ) reservoir of clean fresh water, containing approximately $20 \%$ of the available world's liquid fresh water (Martens, 1997; Yoshii, 1999). Lake Baikal has specific abiotic characteristics that distinguish it from all the other freshwater bodies in the world: high oxygen content throughout the entire water column, stable low water temperatures with long seasonal ice coverage on the lake's surface, and super-oligotrophic conditions. The environmental conditions of the lake's open-water and deep-water zones have remained close to their current state for the last 2-4 million years (Kozhova and Izmest'eva, 1998). As a unique ecosystem with exceptionally high degrees of biological diversity and endemism, Lake Baikal was designated a UNESCO World Heritage Site. To date, 2595 animal species from Lake Baikal have been described, approximately $80 \%$ of which are endemic (Timoshkin, 2001).

Among macroinvertebrates, the highest number of species in the lake is presented by amphipods. The diversity of amphipods in Lake Baikal is very high: currently, 276 species and

78 subspecies (over $10 \%$ of the total species diversity of fauna of Lake Baikal; over $15 \%$ of all recognized amphipod species from fresh or inland waters world-wide), grouped in 7 families and 41 genera, have been found in the lake (Väinölä et al., 2008; Takhteev, 2015). Amphipods inhabit all depths of Baikal, including littoral (0-20 m), sublittoral (20-70 m), supra-abyssal (70$250 \mathrm{~m})$ and abyssal $(250-1640 \mathrm{~m})$; the last two depths are typically grouped as a deep-water zone (Kozhov, 1962). The age and geographical isolation of this group create excellent opportunities for exploring the diversity and evolution of host-parasite relationships.

62 Fungi kingdom and infect a wide range of hosts from invertebrates to humans (Keeling and Fast,

63 2002; Smith, 2009; Issi et al., 2012; Gismondi et al., 2012; Stentiford et al., 2013; Bojko et al., 
64 2016). The number of described species of Microsporidia is more than 1300, and the various 65 species belong to approximately 187 genera, 50 of which are found in aquatic arthropods 66 (Stentiford et al. 2013; Weiss and Becnel, 2014). Some microsporidian species may influence the 67 sex ratio of arthropod populations (Terry et al., 1998; Ironside et al., 2003; Ironside and 68 Alexander, 2015), the behaviour of the host, and the host population dynamics (Dunn and Smith, 69 2001). For example, a selective sexual behaviour is described for amphipod species Gammarus 70 duebeni Liljeborg, 1852. The males of this species infected by Microsporidia are only able to 71 hold down infected females for breeding (Dunn et al., 2006). Microsporidia can be transmitted 72 horizontally, vertically or both ways (Terry et al., 2004; Smith, 2009). They have been found to 73 infect muscles, gonads, intestinal walls, hepatopancreas, haemocytes, and other organs (Kelly 74 and Anthony, 1979; Weiss and Becnel, 2014). the basic principles of coevolution of the host-parasite system and distribution of parasites among evolutionary close species, only a few papers have been published on the microsporidian diversity in the lake's fauna. The study of Microsporidia in Baikal amphipods began in 1967 when Nosema kozhovi was found in intestinal epithelium of Brandtia latissima lata (Dyb., 1874) 80 (Lipa, 1967). The first molecular genetic studies of Microsporidia were performed in the 21st century. Six endemic and one cosmopolitan microsporidian species (Dictyocoela duebenum) were detected in the Baikal amphipod Gmelinoides fasciatus (Stebbing, 1899; Kuzmenkova et al., 83 2008), and 100 new gene isolates of Microsporidia in 31 species of amphipods of Lake Baikal 84 were discovered by molecular methods (Smith et al., 2008). A recent study provided the first 85 glimpse at horizontal distribution and exchange of Microsporidia between Baikal littoral and 86 non-Baikal amphipods, which indicated frequent introductions of the parasites into Lake Baikal 
87 ecosystem and high homogeneity of Microsporidia between species of endemic hosts in the

88 coastal zone (Ironside and Wilkinson, 2017).

89 However, most previous studies utilized the whole individuals or soft amphipod tissues

90 for amplification of microsporidian DNA, which does not rule out the possibility of

91 contamination. To avoid this problem, our group recently conducted a study using molecular

92 genetic techniques (SSU rDNA sequencing) to detect Microsporidia in circulatory system of

93 several endemic amphipod species from Lake Baikal (Madyarova et al., 2015). Searching

94 directly in the haemolymph minimizes the possibility of identifying SSU rDNA of Microsporidia

95 located on exoskeleton, in gut lumen or inside parasites of the amphipods and can guarantee that

96 the found Microsporidia are parasitic directly to the amphipod species studied. Moreover, using

97 haemolymph provides a unified way of treating amphipods of very different sizes, including

98 small species and young individuals.

Spatial variations, especially vertical distribution, in biodiversity of Microsporidia in

100 Lake Baikal amphipods remain poorly investigated. Thus, the aim of the current study was to

101 search for diversity of Microsporidia in the haemolymph of endemic amphipods inhabiting

102 littoral, sublittoral and deep-water zones of the lake in all three basins of Baikal: Southern,

103 Central and Northern.

\section{Materials and Methods}

106 Sampling and location 
108 points of Lake Baikal was used (Table S1). The following seven species were collected at depths

109 of 0-1 m using a hand net in the period from 2011 to 2016: Eulimnogammarus verrucosus, E.

110 cyaneus, E. marituji, E. vitatus, E. maaki, E. viridis olivaceus, Pallasea cancelus. The other

111 amphipod species were sampled from depths of 20-200 m: Acanthogammarus victorii maculosus,

112 A. flavus, A. lappaceus longispinus, A. godlewskii, A. brevispinus, A. reicherii, Carinurus belkini,

113 Garjajewia cabanisi, Propachygammarus maximus, Ommatogammarus carneolus

114 melanophthalmus, Parapallasea lagovskii, P. puzyllii, P. brandtia, P. kesslerii, P. grubii. The

115 latter group of species was collected during the expeditions in 2014 and 2016 using a trawl,

116 dredge and deep-water traps with rotten fish installed at a depth of $200 \mathrm{~m}$. In this work, only

117 benthic amphipod species were studied. The chosen amphipod species are not endangered or 118 protected.

119 Species determination was performed according to the identification key (Bazikalova, 120 1945; Takhteev and Didorenko, 2015).

121 The collections cover all three of Lake Baikal's basins: the Southern (Listvyanka, Bolshie 122 Koty, Port Baikal), the Central (Olkhon Island, Kharauz, Ushkany Islands) and the Northern 123 (Kotelnikovskiy Cap), including both the Western (Listvyanka, Bolshie Koty, Port Baikal) and 124 Eastern (Kharauz) shores (Fig. 1). Around Olkhon Island, five sampling points were screened: 125 Burkhan Cape, Cape Umysh-Tame, Olkhon Gate, Kharantsy Island and Peschanka Bay. The 126 Lake Baikal's basins and the Angara River act as natural geographic barriers for benthic 127 amphipods (Mashiko, 2000; Gomanenko et al., 2005). No specific permissions were required for 128 sampling of amphipods in these locations. 
Haemolymph extraction was performed from live amphipods in a laboratory using a glass

132 capillary. Each sample subsequently used for DNA extraction (volumes ranging from 50 to 100

$133 \mu \mathrm{l})$ contained haemolymph collected from one or pooled from several individuals of the same

134 species. The number of individuals per sample depended on the size of the amphipods (1-50

135 individuals; see Table S1 for details). Isolated haemolymph samples were stored in liquid 136 nitrogen.

DNA extraction and PCR

Total DNA extraction from individual or pooled haemolymph was performed using the was determined using the UV spectrophotometer UNICO 2802 (UNICO, USA). molecular phylogenetic marker. Amplification was performed in the nested PCR with universal

144 primers for Microsporidia: V1f: 5'-CACCAGGTTGATTCTGCCTGAC-3' (Weiss et al., 1994); 145 1342r: 5'-ACGGGCGGTGTGTACAAAGAACAG-3' (McClymont et al., 2005); 18sf: 5'146 GTTGATTCTGCCTGACGT-3' (Baker et al., 1995); and 981r: 5'-

147 TGGTAAGCTGTCCCGCGTTGAGTC-3' (MacNeil et al., 2003). Each PCR was performed in a

148 Gradient Thermocycler (Biometra, Germany) in a volume of $25 \mu l$ and contained 1X PCR buffer, $1496.25 \mathrm{pmol}$ of each dNTP, $2.5 \mathrm{U}$ SynTaq DNA polymerase, $6.25 \mathrm{pmol} \mathrm{MgCl}_{2}, 10 \mathrm{pmol}$ primers, 3 $150 \mu \mathrm{l}$ of DNA template, and deionized water. The conditions for the first round were $95^{\circ} \mathrm{C}$ for $5 \mathrm{~min}$, 151 followed by 40 cycles of $95^{\circ} \mathrm{C}$ for $30 \mathrm{sec}, 55^{\circ} \mathrm{C}$ for $30 \mathrm{sec}$, and $72^{\circ} \mathrm{C}$ for $90 \mathrm{sec}$, and then $72^{\circ} \mathrm{C}$ 
152 for $7 \mathrm{~min}$. Conditions for the second round of PCR were $95^{\circ} \mathrm{C}$ for $5 \mathrm{~min}$, followed by 35 cycles

153 of $95^{\circ} \mathrm{C}$ for $30 \mathrm{sec}, 52^{\circ} \mathrm{C}$ for $30 \mathrm{sec}$, and $72^{\circ} \mathrm{C}$ for $1 \mathrm{~min}$, followed by $72^{\circ} \mathrm{C}$ for $7 \mathrm{~min}$.

154 The PCR products of the second round were visualized in $1 \%$ agarose gels, and products

155 of the expected size were excised from the gel and purified by ethanol and sodium acetate

156 precipitation (Sambrook et al., 1989). Sequencing of the amplified DNA fragments was

157 performed using Genetic Analyzer 3500 xL (Applied Biosystems, Japan) with the BigDye

158 Terminator Cycle Sequencing kit v.3.1 (Applied Biosystems, USA).

159

160

Nucleotide sequence analysis, phylogenetic reconstruction and statistical analysis

161

The obtained sequences were identified with NCBI nucleotide BLAST with default

162

parameters against the nt database (last accessed 2018/05/17). The best B hit belonging to a

163 sample identified in other studies was chosen to describe the samples (Table S2).

The sequences were aligned with the MAFFT 7.397 E-INS-i strategy (Katoh et al., 2009) and then trimmed with Gblocks (Castresana et al., 2000) accessed through the Phylogeny.fr web interface (Dereeper et al., 2008) with all options for less stringent selection checked. The resulting alignment (Alignment S1) contained 514 bases. Nucleotide substitution models were evaluated with jModelTest 2.1.10 (Guindon and Gascuel, 2003; Darriba et al., 2012). The best model according to Bayesian information criterion (BIC) score was $\mathrm{TrN}+\mathrm{G}$ with $\mathrm{GTR}+\mathrm{G}$ falling very close behind. As the formed model was not available in RAxML, GTR $+\mathrm{G}$ was used for all

171 calculations. The phylogenetic tree was reconstructed with BEAST 2.5 (Bouckaert et al., 2014)

172 for $10,000,000$ generations with sampling every $1,000^{\text {th }}$ tree. After this run, ESS value was close 173 to 150 , indicating acceptable convergence. In addition, we reconstructed the tree with RAxML 
174 8.2.11 (Stamatakis, 2014) under the GTRGAMMA model and 5,000 rapid boostrap generations.

175 RAxML bootstrap results were reanalysed with the tree obtained with BEAST to get comparable

176 support rates for the nodes. Raw trees obtained with BEAST and RAxML are shown in Tree S1

177 and Tree S2, respectively. The results were visualized in FigTree 1.4 .2

178 (http://tree.bio.ed.ac.uk/software/figtree/) and Dendroscope, and Fig. 2 was prepared with the

179 ggtree package (Yu et al., 2017) for R (R Core team, 2017) and Inkscape (inkscape.org).

180 Simpson's diversity index was calculated using the diversity function (option index set to 181 invsimpson) of the vegan package (Dixon, 2003) for R. Fisher's exact test was implemented with 182 the stats package for $\mathrm{R}$.

183

184

\section{Results}

We screened the haemolymph of 22 species (Table S1) of endemic amphipods from Lake

Baikal and found microsporidian DNA in two littoral (E. verrucosus, E. cyaneus), two

187 littoral/sublittoral (P. cancellus, E. marituji) and two sublittoral/deep-water species (A. lappaceus

188 longispinus, A. victorii maculosus). A total of over 1,000 individual amphipods were analysed

189 (Table S1). Twenty nucleotide sequences of SSU rDNA belonging to the Cucumispora,

190 Dictyocoela, Enterocytospora-like groups and unassigned Microsporidia were obtained from the

191 haemolymph of the six endemic amphipod species sampled from depths of 0-60 m at Southern

192 Lake Baikal's basin (only the Western shore) and at Central Baikal (Table S2). Only one

193 microsporidian isolate has been identified in each positive pooled haemolymph sample. The

194 phylogenetic tree (Fig. 2) reconstructed using these and some other published microsporidian

195 sequences (Alignment S1) shows clustering of the DNA identified in the current study to four 
196 groups.

Three microsporidian DNA sequences were found in the haemolymph of E. cyaneus 198 (sampled at 0-1 $\mathrm{m}$ in the Southern Baikal), and one was found in A. victorii maculosus (sampled 199 at 53-60 $\mathrm{m}$ in the Central Baikal). These four sequences are presented as a single cluster on the 200 phylogenetic tree marked as Cucumispora-like (C) and are similar to taxonomically defined 201 Cucumispora isolates (Ovcharenko et al., 2010; Bojko et al., 2015, 2017b) as well as 202 microsporidian sequences found earlier in some other endemic amphipods of Lake Baikal, such 203 as P. cancellus (KM977842, KM977843, KM977844, KM977845, KM977846; Madyarova et al., 2015), Acanthogammarus victorii (FJ756173), Garjajewia cabanisii (FJ755959) and 205 Pallaseopsis kessleri (FJ756022).

The other microsporidian DNA from one haemolymph sample of $P$. cancellus, three samples of E. verrucosus (both sampled at $0-1 \mathrm{~m}$ in the Southern Baikal) and two of $A$. lappaceus longispinus (sampled at 25-35 $\mathrm{m}$ in the Central Baikal) were clustered with those of Microsporidia of the recently defined (Bacela-Spychalska et al., 2018) genus Dictyocoela (D), namely D. duebenum (Grabner et al., 2015) and D. berillonum. Representatives of Dictyocoela

211 were found earlier in an endemic Baikal amphipod A. lappaceus (KM977839; Madyarova et al., 212 2015).

Two more sequences amplified from Eulimnogammarus verrucosus haemolymph

214 clustered with other isolates of the Enterocytospora-like clade (E), such as Enterocytospora 215 artemiae (JX915760; Rode et al., 2013a), Globulispora mitoportans (KT762153; Vávra et al., 216 2016) and recently described Parahepatospora carcini (KX757849; Bojko et al., 2017a). A 217 similar sequence was also found in an endemic Baikal amphipod Micruropus wahlii (FJ756186). 
219 from four different habitats, Listvyanka, Bolshie Koty, Port Baikal (Southern Baikal) and

220 Burkhan Cape (Central Baikal), clustered with other microsporidian sequences previously

221 amplified from Baikal endemic amphipods (FJ756111 from Dorogostaiskia parasitica and

222 FJ755992 from Odontogammarus calcaratus). This cluster is designated as unclassified

223 Microsporidia (uM).

As we have data for seven different locations, we have calculated Simpson's diversity 225 index for the groups of amphipods defined according to the phylogenetic tree and these locations (Fig. S1). Our samples are not big enough to draw any conclusions, as we quite predictably saw higher diversity in locations with higher numbers of analysed pools, but further studies may help clarify this issue.

\section{Discussion}

The microsporidian DNA sequences found in the haemolymph of amphipods from Lake

Baikal during this study belong to four clusters: Cucumispora-, Dictyocoela-, Enterocytospora-

233 like, as well as some unclassified Microsporidia. Some other sequences belonging to the

234 Cucumispora-like and Dictyocoela-like clusters, as well as to unclassified Microsporidia were 235 also identified in our previous work (Madyarova et al., 2015). Apart from these similarities, there 236 were also some differences, as in the earlier work we also identified representatives of the genus

237 Nosema (N) in Baikal amphipods E. verrucosus from Listvyanka (Madyarova et al., 2015), but in 238 the current study, these microsporidian species were not found at all. 
240 relatively high infection ( $\sim 30 \%$ of pools) by Microsporidia of groups Nosema/Vairimorpha-

241 (NV), Dictyocoela- (D), Enterocytospora-like (E) and unclassified Microsporidia (uM), while in

242 summer 2016 only one infected pool $(\sim 3 \%)$ was identified in this location and corresponded to

243 an unclassified Microsporidia (uM). We have compared the largest samples with exact Fisher's

244 test (5 out of $18 v$ s. 1 out of 33) and found that the difference was statistically significant ( $\mathrm{p}=$

245 0.017). Sampling of Microsporidia during summer and autumn (2015 and 2016) at other points

246 (Port Baikal, Bolshie Koty and Burkhan Cape) also demonstrated relatively low infection (no

247 more than $13 \%$ of pools) only by unclassified Microsporidia. It is interesting to note that two

248 highest infection rates belonged to pools sampled in winter, the reproduction season of $E$.

249 verrucosus (Bazikalova, 1941). Generally, by comparing the percentage of infected haemolymph

250 pools of different amphipod species from chosen sampling points (Table S1), we can conclude

251 that the proportion of infected individuals can vary significantly.

The species diversity of the obtained samples is also interesting in the context of 253 worldwide diversity of microsporidian parasites of amphipods. Microsporidian SSU rDNA 254 nucleotide sequences similar to the $\mathrm{C}$ group in our analysis (Fig. 2) were also found in Gammarus chevreuxi Sexton, 1913 from the Avon River in the UK (AJ438962) (Terry et al., 2004). The identified sequences of the D group are similar to the Dictyocoela duebenum isolate 775 (FN434091), which was previously found in Gammarus duebeni from Iceland (Krebes et al., 258 2010), and the Dictyocoela muelleri isolate (AJ438955) found in Gammarus duebeni celticus

259 from Ireland (Terry et al., 2004). The Enterocytospora-like sequences are similar to the 260 sequences of Enterocytospora artemiae found in Artemia franciscana monica from Mono Lake, 261 USA (Rode et. al., 2013b). These results may suggest that microsporidian distribution in Baikal 262 amphipods is similar to that in amphipods and other crustaceans from other water bodies. 
264 should note that similar and identical sequences of microsporidian DNA were found in

265 amphipods inhabiting different depths and basins of the lake. Two microsporidian sequences

266 from $P$. cancellus (KM977844 and KM977846) were identical to sequences from completely

267 different amphipod species G. cabanisi (FJ755959) and D. parasitica (FJ756113) (Table S2; Fig.

268 2). Almost identical DNA of Microsporidia that belong to the group $C$ were found at sampling 269 depths 0-1 m of Southern Baikal (KT956054, KR080135, KT956053 from E. cyaneus and

270 KM977844 from P. cancellus) and depths of 54-60 m of Central Baikal (KT956063 from $A$.

271 victorii maculosus). Similar sequences of Microsporidia of the group D are found at depths of 0-

$2721 \mathrm{~m}$ (E. marituji, E. verrucosus and P. cancellus from the Southern Baikal) and at 25-35 $\mathrm{m}(A$.

273 lappaceus longispinus from the Central Baikal). Additionally, amphipods of species E.

274 verrucosus from Southern and Central Baikal were infected by microsporidia with almost

275 identical SSU rDNA belonging to some unclassified Microsporidia (uM). So, similar

276 microsporidian isolates infect different hosts at different depths and locations. There are several

277 possible explanations for this fact. Amphipods are omnivorous animals and can feed on other 278 amphipods of different or the same species. Moreover, Baikal amphipods are characterized by 279 high vertical and horizontal mobility: a significant part of the analysed species (E. marituji, $P$. 280 cancellus, A. lappaceus longispinus and others) can be found in a range of depths of at least 281 several dozen meters and can participate in nocturnal vertical migrations observed for many 282 benthic animals in Baikal (Bazikalova, 1945; Karnaukhov et al., 2016); also, in Lake Baikal 283 there are eurybathic scavenger amphipods (like Ommatogammarus flavus and O. albinus), found 284 in depth ranges of several hundred meters (Bazikalova, 1945), which may serve as additional 285 "carriers" of infections in the benthic community. 
287 Microsporidia found in circulatory system of endemic amphipods from Lake Baikal and host

288 species, geographic location or depth. This result corroborates previous studies (Madyarova et al., 289 2015; Ironside \& Wilkinson, 2017).

\section{Conclusions}

The sequence isolates that we have identified during our study belong to four clusters and

Baikal and other water reservoirs. No specificity in distribution of Microsporidia was identified

connectivity of individuals within species and between species of Lake Baikal amphipods.

However, search for Microsporidia in amphipods at greater depths $(200-1600 \mathrm{~m})$ is still necessary to confirm the observed homogeneity in distribution of these parasites.

\section{Acknowledgements} and fixation of samples, identifying species of amphipods and their valuable advice. We are comments on the manuscript. 


\section{References}

308 Bacela-Spychalska, K., Wróblewski, P., Mamos, T., Grabowski, M., Rigaud, T., Wattier, R., ... 309 \& Ovcharenko, M., 2018. Europe-wide reassessment of Dictyocoela (Microsporidia) infecting native and invasive amphipods (Crustacea): molecular versus ultrastructural traits. Scientific reports, 8, 8945.

312

313

314

315

316

317

Baker, M. D., Vossbrinck, C. R., Didier E. S., Maddox J. V., Shadduck J. A., 1995. Small subunit ribosomal DNA phylogeny of various microsporidia with emphasis on AIDSrelated forms. Journal of Eukaryotic Microbiology, 42, 564-570.

Bazikalova, A. Y. 1945. Amphipods of Lake Baikal. Proceedings of Baikal Limnological Station, $11,1-440$.

Bojko, J., Dunn, A.M., Stebbing, P.D., Ross, S.H., Kerr, R.C. and Stentiford, G.D., 2015. Cucumispora ornata n. sp. (Fungi: Microsporidia) infecting invasive 'demon shrimp' (Dikerogammarus haemobaphes) in the United Kingdom. Journal of invertebrate pathology, 128, 22-30.

Bojko, J., Clark, F., Bass, D., Dunn, A.M., Stewart-Clark, S., Stebbing, P.D. and Stentiford, G.D., 2017a. Parahepatospora carcini n. gen., n. sp., a parasite of invasive Carcinus maenas with intermediate features of sporogony between the Enterocytozoon clade and other Microsporidia. Journal of invertebrate pathology, 143, 124-134.

Bojko, J., Bącela-Spychalska, K., Stebbing, P. D., Dunn, A. M., Grabowski, M., Rachalewski, M. Stentiford, G. D., 2017b. Parasites, pathogens and commensals in the "low-impact" nonnative amphipod host Gammarus roeselii. Parasites \& Vectors, 10, 1-15. 
328 Bouckaert, R., Heled, J., Kühnert, D., Vaughan, T., Wu, C-H., Xie, D., Suchard, M. A., Rambaut, 329 A., \& Drummond, A. J. (2014). BEAST 2: A software platform for Bayesian evolutionary analysis. PLoS Computational Biology, 10, e1003537.

331 Castresana, J., 2000. Selection of conserved blocks from multiple alignments for their use in 332 phylogenetic analysis. Molecular Biology and Evolution, 17, 540-552.

333

335

336

338

340

342

Darriba, D., Taboada, G.L., Doallo, R., Posada, D., 2012. jModelTest 2: more models, new heuristics and parallel computing. Nature Methods, 9, 772.

Dereeper, A., Guignon, V., Blanc, G., Audic, S., Buffet, S., Chevenet, F., Dufayard, J.F., Guindon, S., Lefort, V., Lescot, M. and Claverie, J.M., 2008. Phylogeny. fr: robust phylogenetic analysis for the non-specialist. Nucleic acids research, 36, W465-W469.

Dixon, P., 2003. VEGAN, a package of $\mathrm{R}$ functions for community ecology. Journal of Vegetation Science, 14(6), pp.927-930.

Dunn, A.M., Smith, J.E., 2001. Microsporidian life cycles and diversity: the relationship between virulence and transmission. Microbes and Infection, 3, 381-388.

Dunn, A.M., Hogg, J.C., Hatcher, M.J., 2006. Transmission and burden and the impact of temperature on two species of vertically transmitted microsporidia. International Journal for Parasitology, 36, 409-414.

Gismondi, E., Rigaud, T., Beisel, J. N., Cossu-Leguille, C., 2012. Microsporidia parasites disrupt the responses to cadmium exposure in a gammarid. Environmental Pollution, 160, 17-23.

Gomanenko, G. V., Kamaltynov, R. M., Kuzmenkova, Z. V., Berenos, K., Sherbakov, D. Y., 2005. Population structure of the Baikalian amphipod Gmelinoides fasciatus (Stebbing). 
Russian Journal of Genetics, 41, 907-912.

350 Grabner, D. S., Weigand, A. M., Leese, F., Winking, C., Hering, D., Tollrian, R., Sures, B., 2015. 351 Invaders, natives and their enemies: distribution patterns of amphipods and their 352 microsporidian parasites in the Ruhr Metropolis, Germany. Parasites \& vectors, 8, 419.

353 Guindon, S. and Gascuel, O., 2003. A simple, fast and accurate method to estimate large phylogenies by maximum-likelihood. Systematic Biology, 52, 696-704.

355

356

357

358

359

360

361

362

363

364

365

366

367

Issi, I. V., Tokarev, Y. S., Seliverstova, E. V., Voronin V. N., 2012. Taxonomy of Neoperezia chironomi and Neoperezia semenovaiae comb. nov. (Microsporidia, Aquasporidia): Lessons from ultrastructure and ribosomal DNA sequence data. European Journal of Protistology, 48, 17-29.

Ironside, J. E., Alexander, J., 2015. Microsporidian parasites feminise hosts without paramyxean co-infection: support for convergent evolution of parasitic feminisation. International journal for parasitology, 45, 427-433.

Ironside, J. E., Dunn, A. M., Rollinson, D., Smith, J. E., 2003. Association with host mitochondrial haplotypes suggests that feminizing microsporidia lack horizontal transmission. Journal of evolutionary biology, 16, 1077-1083.

Ironside, J.E., Wilkinson, T.J., 2017. Accumulation and exchange of parasites during adaptive radiation in an ancient lake. International Journal for Parasitology, S00207519(17)30349-1.

Karnaukhov, D. Y., Bedulina, D. S., Kaus, A., Prokosov, S. O., Sartoris, L., Timofeyev, M. A., Takhteev, V. V., 2016. Behaviour of Lake Baikal amphipods as a part of the night 
migratory complex in the Kluevka settlement region (south-eastern Baikal). Crustaceana, 89, 419-430.

372

373

Katoh, K., Asimenos, G., Toh, H., 2009. Multiple alignment of DNA sequences with MAFFT. Bioinformatics for DNA sequence analysis, 537, 39-64.

Keeling, P. J., Fast, N. M., 2002. Microsporidia: biology and evolution of highly reduced intracellular parasites. Annual Reviews in Microbiology, 56, 93-116.

Kelly, J. F., Anthony, D. W., 1979. Susceptibility of spores of the microsporidian Nosema algerae to sunlight and germicidal ultraviolet radiation. Journal of invertebrate pathology, 34, 164-169.

Kozhov, M. M., 1962. Biology of Lake Baikal. Publishing house of Academy of Sciences of the USSR, Moscow.

Kozhov, M. M., Kozhova O. M., Izmest'eva L. R. Izmest'eva L. R., 1998. Lake Baikal: evolution and biodiversity. Backhuys Publishers.

Krebes, L., Blank, M., Frankowski, J., Bastrop, R., 2010. Molecular characterisation of the Microsporidia of the amphipod Gammarus duebeni across its natural range revealed hidden diversity, wide-ranging prevalence and potential for co-evolution. Infection, Genetics and Evolution, 10, 1027-1038.

Kuzmenkova, Z.V., Sherbakov D.U., Smith J.E., 2008. Diversity of microsporidia, that parasitize on baikal amphipods Gmelinoides fasciatus from different populations. The bulletin of Irkutsk State University. Series”Biology, Ecology", 1, 56-61.

Lipa, J. J., 1967. Nosema kozhovi sp. n., a new microsporidian parasite of Brandtia lata lata 

(Crustacea, Gammaridae) of Baical Lake. Acta protozool, 5, 93-97.

392 MacNeil, C., Dick, J. T., Hatcher, M. J., Terry, R. S., Smith, J. E., Dunn, A. M., 2003. Parasite393 mediated predation between native and invasive amphipods. Proceedings of the Royal Society of London B: Biological Sciences, 270, 1309-1314.

Madyarova, E. V., Adelshin, R. V., Dimova, M. D., Axenov-Gribanov, D. V., Lubyaga, Y. A., Timofeyev, M. A., 2015. Microsporidian parasites found in the hemolymph of four

Martens, K., 1997. Speciation in ancient lakes. Trends in Ecology \& Evolution, 12, 177-182.

Mashiko, K., 2000. Insights into the mechanism of speciation in gammarid crustaceans of Lake Baikal using a population-genetic approach. Advances in Ecological Research, 31, 221-

McClymont, H. E., Dunn, A. M., Terry, R. S., Rollinson, D., Littlewood, D. T. J., Smith, J. E., 403 2005. Molecular data suggest that microsporidian parasites in freshwater snails are diverse. International journal for parasitology, 35, 1071-1078.

405

Ovcharenko, M.O., Bacela, K., Wilkinson, T., Ironside, J.E., Rigaud, T. and Wattier, R.A., 2010.

407 Cucumispora dikerogammari n. gen. (Fungi: Microsporidia) infecting the invasive 408 amphipod Dikerogammarus villosus: a potential emerging disease in European rivers. Parasitology, 137(2), pp.191-204. Statistical Computing, Vienna, Austria. URL https://www.R-project.org/.

411 Rode, N. O., Landes, J., Lievens, E. J., Flaven, E., Segard, A., Jabbour-Zahab, R., ... \& 
Lenormand, T., 2013a. Cytological, molecular and life cycle characterization of Anostracospora rigaudi ng, n. sp. and Enterocytospora artemiae ng, n. sp., two new microsporidian parasites infecting gut tissues of the brine shrimp Artemia. Parasitology, 140(9), 1168-1185.

Rode, N. O., Lievens, E. J., Segard, A., Flaven, E., Jabbour-Zahab, R., Lenormand, T., $2013 b$. Cryptic microsporidian parasites differentially affect invasive and native Artemia spp.

Sambrook, J., Fritsch, E. F., Maniatis, T., 1989. Molecular cloning: a laboratory manual (No. Ed. International journal for parasitology, 43, 795-803.

Smith, J. E., 2009. The ecology and evolution of microsporidian parasites. Parasitology, 136, 2). Cold Spring Harbor laboratory press.

Smith, J. E., Yang Q., Kamaltynov R. M., Sherbakov D. Y., 2008. Evolutionary interactions between microsporidia and their hosts: Lessons from an ancient lake. 41st Annual Meeting of the Society for Invertebrate Pathology and 9th International Conference on

Stamatakis A., 2014. RAxML version 8: a tool for phylogenetic analysis and post-analysis of 428 large phylogenies. Bioinformatics, 30, 1312-1313. diverse, dynamic, and emergent pathogens in aquatic systems. Trends in parasitology, 29, 567-578.

432 Takhteev, V. V., Berezina, N. A., Sidorov, D. A., 2015. Checklist of the Amphipoda (Crustacea) 
from continental waters of Russia, with data on alien species. Arthropoda Selecta, 24, $335-370$.

435 Terry, R. S., Smith, J. E., Dunn, A. M., 1998. Impact of a novel, feminising microsporidium on 436 its crustacean host. Journal of Eukaryotic Microbiology, 45, 497-501.

Terry, R.S., Smith, J.E., Sharpe, R.G., Rigaud, T., Littlewood, D. T.J., Ironside, J.E., 2004.

438

439

441 442

Weiss, L. M., 1994. Utility of microsporidian rRNA in diagnosis and phylogeny: a review. Folia parasitologica, 41, 81-90.

Vávra, J., Hyliš, M., Fiala, I., \& Nebesářová, J. (2016). Globulispora mitoportans ng, n. sp., (Opisthosporidia: Microsporidia) a microsporidian parasite of daphnids with unusual spore organization and prominent mitosome-like vesicles. Journal of invertebrate pathology, 135, 43-52.

$$
\text { parasitologica, 41, 81-90. }
$$

Weiss, L. M., Becnel, J. J., 2014. Microsporidia: Pathogens of Opportunity. John Wiley \& Sons.

Yoshii, K., 1999. Stable isotope analyses of benthic organisms in Lake Baikal. Hydrobiologia, 
454 $411,145-159$.

455 Yu G, Smith D, Zhu H, Guan Y, Lam TT (2017). ggtree: an R package for visualization and 456 annotation of phylogenetic trees with their covariates and other associated data.

457 Methods in Ecology and Evolution, 8, 28-36

458 


\section{Figure legends}

460

461 Figure 1. Sampling sites for amphipod collection in Lake Baikal. Grey dots correspond to sites 462 where no infected amphipods were found, while black dots mark places where microsporidian DNA was identified in amphipod haemolymph. The bathymetric map of Lake Baikal was taken

464 from http://users.ugent.be/ mdbatist/intas/intas.htm and modified with CorelDRAW.

465 Figure 2. Bayesian phylogenetic tree of Microsporidia identified in amphipods of Lake Baikal 466 and some other crustaceans. The tree contains the following clusters:

467 Enterocytozoonidae\&Hepatosporidae-like (EH), Enterocytospora- (E), Cucumispora- (C), 468 Dictyocoela- (D), Nosema-Vairimorpha-like (NV), and some unclassified Microsporidia (uM), 469 Nosema $(\mathrm{N})$. Branch lengths are drawn to scale. Grey semi-circles mark nodes with bootstrap 470 support $>70 \%$, and red semi-circles mark those with posterior probability $>0.7$. Baikal shapes 471 mark microsporidian sequences amplified from Lake Baikal amphipods, and samples obtained in 472 this work are in blue font. The alignment used to build this tree is presented in Alignment S1.

\section{Supplementary materials}

Supplemental Table S1. All analysed samples of haemolymph of amphipods collected in Lake 476 Baikal.

Supplemental Table S2. All microsporidian DNA identified in haemolymph of amphipods

478 collected in Lake Baikal. It contains sequences obtained both in the current study and in 479 (Madyarova et al., 2015). Columns A-H describe samples obtained in our work, while columns 
480 H-M describe their closest their closest hits in the NCBI database. E-values equal to 0 represent 481 values lower than $10^{-200}$.

482 Supplemental Alignment S1. Raw alignment of microsporidian DNA sequences used for 483 construction of the phylogenetic tree on Fig. 2.

484 Supplemental Tree S1. Bayesian tree obtained from the Alignment S1.

485 Supplemental Tree S2. Maximum likelihood bootstrap support for the tree obtained from the 486 Alignment S1.

487 Supplemental Figure S1. Inverse Simpson's diversity index for each location and number of 488 samples for each location where microsporidian DNA was detected. The vertical axis features 489 the number of microsporidian isolates. 


\section{Figure 1}

Sampling sites for amphipod collection in Lake Baikal.

Grey dots correspond to sites where no infected amphipods were found, while black dots mark places where microsporidian DNA was identified in amphipod haemolymph. The bathymetric map of Lake Baikal was taken from http://users.ugent.be/ mdbatist/intas/intas.htm and modified with CorelDRAW. 


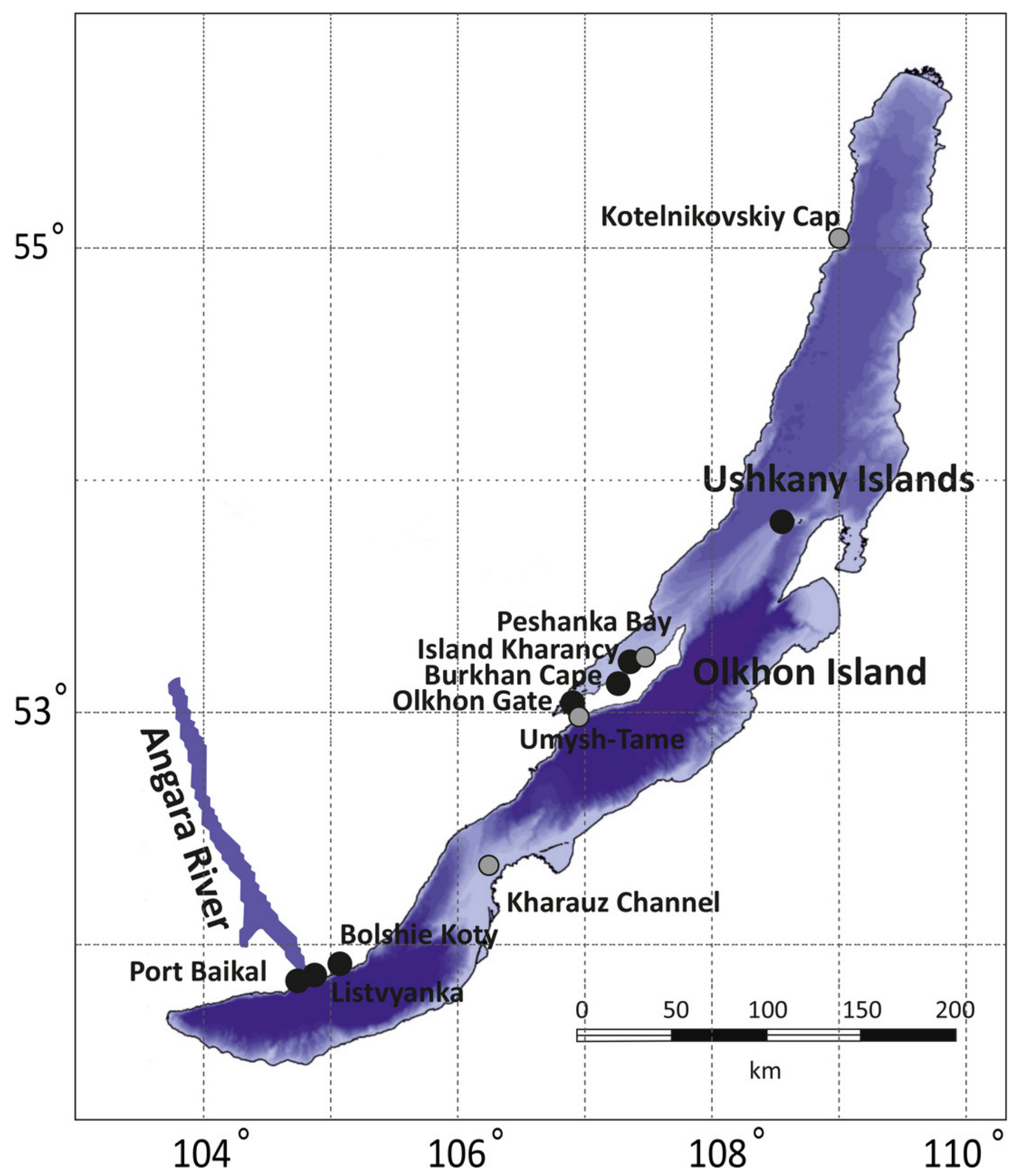




\section{Figure 2 (on next page)}

Bayesian phylogenetic tree of Microsporidia identified in amphipods of Lake Baikal and some other crustaceans.

The tree contains the following clusters: Enterocytozoonidae\&Hepatosporidae-like (EH), Enterocytospora- (E), Cucumispora- (C), Dictyocoela- (D), Nosema-Vairimorpha-like (NV), and some unclassified Microsporidia (UM), Nosema (N). Branch lengths are drawn to scale. Grey semi-circles mark nodes with bootstrap support $>70 \%$, and red semi-circles mark those with posterior probability $>0.7$. Baikal shapes mark microsporidian sequences amplified from Lake Baikal amphipods, and samples obtained in this work are in blue font. The alignment used to build this tree is presented in Alignment S1. 
Bootstrap $>70 \%$ PeerJ

Posterior probability $>0.7$

Baikal samples

Samples obtained in this work

FJ389667 Paranucleospora heridipn isplate FS2g090\%

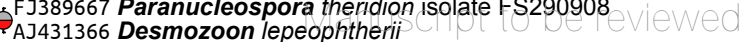
HG005137 Obruspora papernae

JN938583 Uncultured Nucleospora clone AR_MSP_1

GU823485 Uncultured stramenopile clone AB3F14RJ10D09

U78176 Nucleospora salmonis

U10883 Enterocytozoon salmonis

$0.04 \quad$ KF135645 Enterospora nucleophila isolate NUCA3

- FJ756170 Microsporidium sp. BVER2

- HE584634 Enterospora canceri strain RA09010-4

AF023245 Enterocytozoon bieneusi

FJ794867 Microsporidium sp. MIC2

AF394528 Microsporidium sp. isolate DP-1-19

HE584635 Hepatospora eriocheir

JX915760 Enterocytospora artemiae isolate Ea Fang6

FJ756186 Microsporidium sp. BWOH2 WOH1

KT762153 Globulispora mitoportans

FJ756017 Microsporidium sp. BGRE

KT956059 Listv.ev11 (Eulimnogammarus verrucosus)

KT956058 Listv10 (Eulimnogammarus verrucosus)

KX757849 Parahepatospora carcini

KY458988 P.Baik90 (Eulimnogammarus verrucosus)

KY458987 P.Baik87 (Eulimnogammarus verrucosus)

KY458986 P.Baik63 (Eulimnogammarus verrucosus)

KY458989 Burkh.C105 (Eulimnogammarus verrucosus) KY458983 Listv170 (Eulimnogammarus verrucosus)

KY458982 BKoty128 (Eulimnogammarus verrucosus)

FJ756111 Microsporidium sp. BPAR11 PAR

FJ755992 Microsporidium sp. BCAL3 CAL

KT956056 BKoty4 (Eulimnogammarus verrucosus)

KX379715 Nosema sp. LS10M3

KM977840 Listv28 (Eulimnogammarus verrucosus)

KM977841 Listv31 (Eulimnogammarus verrucosus)

L39111 Nosema bombycis

EU267796 Vairimorpha ceraces

- DQ996241 Vairimorpha necatrix

AF141129 Vairimorpha lymantriae

[ KT956054 Listv3 (Eulimnogammarus cyaneus)

KR080135 Listv1 (Eulimnogammarus cyaneus)

- KT956053 BKoty2 (Eulimnogammarus cyaneus)

KM977844 Listv.pc11 (Pallasea cancellus)

- FJ756173 Microsporidium sp. BVIC2 VIC

KT956063 Khar1 (Acanthogammarus victorii maculosus)

[ FJ755959 Microsporidium sp. BALB1 CAB

r. MG063425 Cucumispora sp. isolate KKBI5

FJ756022 Microsporidium sp. BKES3

KM977843 Listv7a (Pallasea cancellus),

KM977842 Listv4 (Pallasea cancellus)

KM977845 Listv12 (Pallasea cancellus)

KM977845 Listv12 (Pallasea cancellus)
KR190602 Cucumispora ornata isolate RA13158

KM977846 Listv16 (Pallasea cancellus)

KY200851 Cucumispora roeselii isolate RA15029

GQ258752 Cucumispora dikerogammari

- KY458985 Olkh.G24 (Acanthogammarus lappaceus longispinus)

[ KY458984 Olkh.G22 (Acanthogammarus lappaceus longispinus),

KT956057 Listv9 (Eulimnogammarus verrucosus)

- KT956065 Listv16 (Eulimnogammarus verrucosus),

KR871380 Dictyocoela duebenum

KP027301 BKoty17 (Eulimnogammarus marituji)

[L KY58981 Listv22 (Eulimnogammarus marituji)]

- KM977839 Ushkan-5 (Acanthogammarus lappaceus longispinus)

KM657354 Dictyocoela berillonum isolate A22A25

KT956064 Listv.ev14 (Eulimnogammarus verrucosus)

KT956060 Listv.pc14 (Pallasea cancellus)

AF056015 Glugea stephani

AF056014 Glugea ameriReaflusviewing PDF | (2018:02:25209:2:0:NEW 3 Jul 2018)

D

ctyocoela-

like

\section{EH}

Enterocytozoonidae \&

Hepatosporidae-like

E

Enterocytospora-like

Microsporidia

Nosema / Vairimorpha-like 